
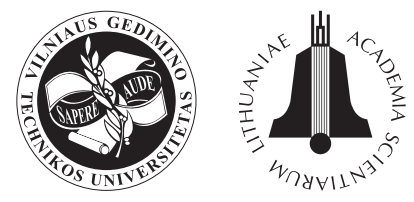

TRANSPORT

2009

24(3): $249-256$

\title{
RESEARCHING AND ANALYZING THE FEATURES OF OIL AND DEMAND FOR TRANSPORTING OIL DERIVATES IN THE AREA OF BELGRADE
}

\author{
Vojkan D. Jovanović ${ }^{1}$, Slaven Tica ${ }^{2}$, Branko Milovanović ${ }^{3}$, Predrag Živanović ${ }^{4}$ \\ Faculty of Transport and Traffic Engineering, University of Belgrade, \\ Vojvode Stepe 305, 11000 Belgrade, Serbia \\ E-mails: ${ }^{1}$ v.jovanovic@sf.bg.ac.rs; ${ }^{2}$ tice@eunet.yu; ${ }^{3}$ b.milovanovic@sf.bg.ac.rs; ${ }^{4}$ p.zivanovic@sf.bg.ac.rs
}

Received 12 December 2008; accepted 3 September 2009

\begin{abstract}
The paper contains a summary of results obtained when researching demand for transporting dangerous goods of class 3 (oil and oil derivates) in the area of the city of Belgrade in 2007. Considering all transport modes used for carrying oil and oil derivates (road, rail and water transport), we present the total quantities of transported goods on a percentage basis. In light of road transport, the paper presents the features of demand for transport in terms of time and space that are a basis for the management of transporting dangerous goods and input to defining transportation routes to dangerous goods. Among the features of demand for transport in terms of time, the paper presents the quantities of goods transported within different months of the year, different week days and different periods of the day. The features of demand for transport in terms of space presented in the paper are goods flow features depending on their origin and the destination of movement in relation to the defined serviced area and the load of traffic network with goods flows.
\end{abstract}

Keywords: dangerous goods, transport, environmental protection, traffic flow, variation, demand for transport.

\section{Introduction}

Transporting dangerous goods is a kind of transport with highest risks and potential danger for population and environment. In order to establish the level of risk, i.e. to be able to manage risk in transporting dangerous goods, the first step that has to be taken is the establishment of the features of demand for transporting dangerous goods within a specific area (Leonelli et al. 2007; Ghazinoory and Kheirkhah 2008; Batarlienè 2007 and 2008). According to the first two of eight steps in danger analysis (United Nations Environment Programme 2000) representing the first phase of risk Management of transporting dangerous goods, dangerous objects and danger are defined. In order to quantify danger (to define the level of danger), it is necessary to establish the general types and quantity of dangerous materials transported within a specific area as well as the features of demand for transport in terms of time and space. Simultaneously, for defining risky objects, it is necessary to establish routes to vehicles used for transporting dangerous goods. This paper contains the summary of results obtained in researching demand for transporting dangerous goods of class 3 (oil and oil derivates) in the area of the City of Belgrade in 2007. The main goal of the article is to define the basic elements of danger analysis, based on which it is possible to analyze consequences and estimate risk. The reason for choosing dangerous goods of class 3 as the subject of research is the fact that this class is the commonest one when considering the transportation of dangerous goods with the estimated $80 \%$ share of the total quantity of dangerous goods carried using all modes of transport within the area of Belgrade.

\section{Features of the Serviced Area}

Belgrade, as the capital of the Republic of Serbia, has 1576124 inhabitants (according to the population census from 2002) and occupies the territory of 322268 hectares. The central area of the city occupies the territory of 77602 hectares and it will be taken as a serviced area for the needs of this paper.

The representation of the serviced area is given in Fig. 1.

Within the central area of the city, the road network is highly developed and its total length makes $863 \mathrm{~km}$, thus it does not represent a restrictive factor in transporting dangerous goods. Table 1 represents road lengths according to their rank and a percentage of the total length of the road network. 


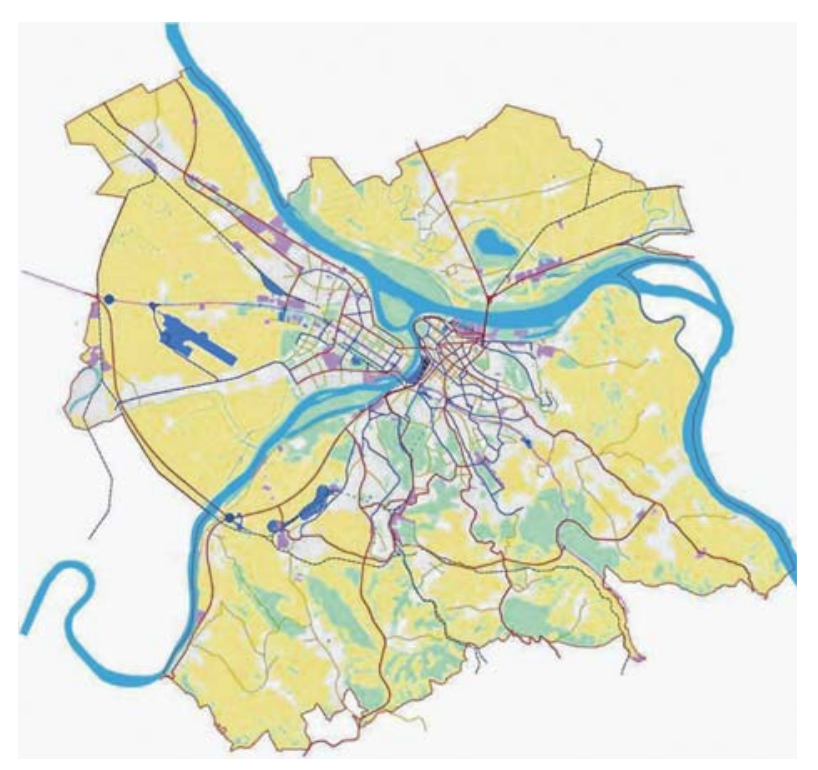

Fig. 1. Serviced area

Table 1. Road length according to their rank

\begin{tabular}{ccc}
\hline Road rank & Length $(\mathrm{km})$ & $\%$ \\
\hline Urban highway & 32.2 & 3.73 \\
\hline Bypass highway & 53.4 & 6.19 \\
\hline Magistral roads & 233.3 & 27.03 \\
\hline I rank streets & 212.4 & 24.61 \\
\hline II rank streets & 275.1 & 31.88 \\
\hline Corridors & 56.6 & 6.56 \\
\hline Total: & $\mathbf{8 6 3 . 0}$ & $\mathbf{1 0 0 . 0 0}$ \\
\hline
\end{tabular}

Source: Skupština grada Beograda 2003.

Within the defined central city area, there are fifteen fixed sources of dangerous goods shown in Fig. 2. Since the paper refers to research on demand for transporting dangerous goods of class 3 , there are 3 sources within the observed area. They are marked with numbers and the zone of influence is presented for each of them. The object marked with number 1 represents Oil Refinery Pancevo from which oil and oil derivates are transported using water, rail and road transport. Number 2 represents oil depository Ada Huja from which oil is transported by road transport while number 3 shows Installation (served by water and road transport).

Beside these sources, oil and oil derivates to the area of Belgrade are also transported from Oil Refinery Novi Sad (water, rail and road transport), Elemir (road transport) and Installations in Smederevo (road transport).

A definition of the fixed sources of dangerous goods of class 3 is of great importance for defining the features of demand for transport in terms of space because they represent the main zones producing dangerous goods of class 3. Also a definition of location and an influence zone of a source represent input to research on the features of demand for transport.

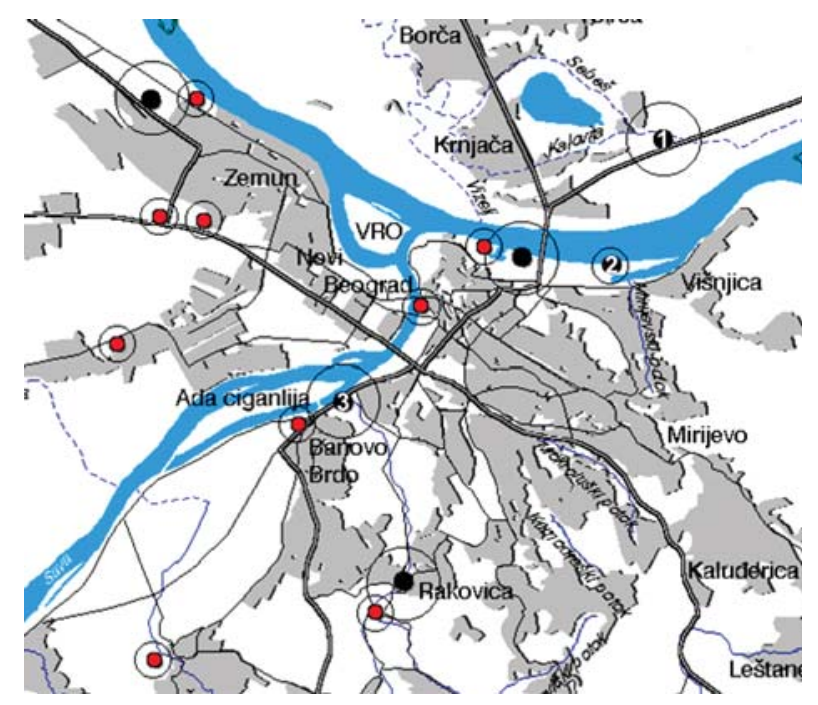

Fig. 2. Sources of dangerous goods

\section{Total Quantity of Oil and Oil Derivates Transported in the Area of Belgrade Considering the Modes and Sources of Transport}

On the basis of the conducted research on the total sample in 2007, 993986659 litres of oil and oil derivates were transported within the area of Belgrade.

A share of transported goods taking into account transport mode (modal split) is shown in Table 2 and Fig. 3.

Table 2. A share of transported goods taking into account transport mode in 2007 (modal split)

\begin{tabular}{ccc}
\hline & Total quantity of goods (litres) & $\%$ \\
\hline Road & 768963219 & 77.36 \\
\hline Rail & 57341465 & 5.77 \\
\hline Water & 167681975 & 16.87 \\
\hline Total & $\mathbf{9 9 3 9 8 6 6 5 9}$ & $\mathbf{1 0 0 . 0 0}$ \\
\hline
\end{tabular}

Taking into account transportation modes used for transporting oil and oil derivates in the area of Belgrade, the greatest share belongs to road transport with 768963219 litres transported in 2007 which represents $77.36 \%$ of the total quantity of goods. Barge transport makes somewhat more than $15 \%$ of total quantity, i.e. $16.87 \%$. Only $5.77 \%$ of the total quantity of goods is transported by rail, i.e. 57341465 litres per year.

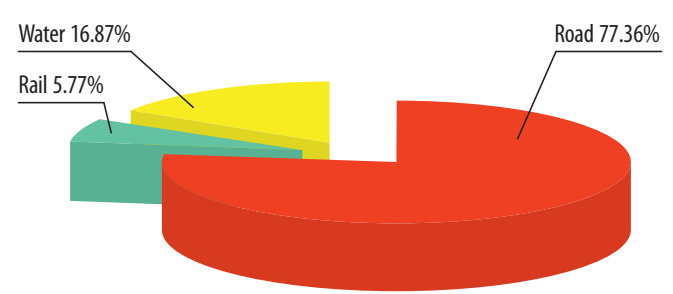

Fig. 3. A share of transported goods taking into account transport mode in 2007 (modal split) 
When observing the share of the total quantity of transported goods in 2007, according to the sources, the data given in Table 3 shows that most of oil and oil derivates for and through the area of Belgrade using all transport modes is transported from Oil Refinery Pancevo -541041060 litres, i.e. $54.43 \%$ of the total quantity of transported goods. 232577880 litres are transported for and through Belgrade from Installations (23.40\% of total quantity) while the remaining $22.17 \%$ is transported from Smederevo (14.95\%) and Refinery Novi Sad (7.22\%).

For the purpose of defining demand for transport in terms of time and space transporting oil and oil derivates by road, first, it is necessary to define the quantities of goods transported by road transport separately for each source. These figures are shown in Table 3 and on the basis of this information, it can be concluded that within the area of Belgrade, the major part of oil and oil derivates is transported from Refinery Pancevo (source 1 in Fig. 1) which is 320384885 litres per year or $41.66 \%$ of the total quantity of goods transported by means of road transport. 232577880 litres per year or $30.25 \%$ are transported from Installations in Belgrade (Cukarica, Ada Huja, Novi Beograd).

Table 3. A share of transported goods according to the sources provided in 2007 considering transportation modes

\begin{tabular}{clcc}
\hline \multirow{2}{*}{ Source } & \multicolumn{1}{c}{$\begin{array}{c}\text { Total quantity of } \\
\text { goods (litres) }\end{array}$} & $\%$ \\
\hline \multirow{2}{*}{ Road } & Refinery Pancevo & 320384885 & 41.66 \\
\cline { 2 - 4 } & Refinery Novi Sad & 67431429 & 8.77 \\
\cline { 2 - 4 } & Belgrade & 232577880 & 30.25 \\
\cline { 2 - 4 } & Smederevo & 148569025 & 19.32 \\
\hline \multirow{2}{*}{ Total } & & $\mathbf{7 6 8 9 6 3 2 1 9}$ & $\mathbf{1 0 0 . 0 0}$ \\
\hline \multirow{2}{*}{ Rail } & Refinery Pancevo & 54229401 & 94.57 \\
\cline { 2 - 4 } Total & Refinery Novi Sad & 3112064 & 5.43 \\
\hline \multirow{2}{*}{ Water } & Refinery Pancevo & $\mathbf{5 7 3 4 1 4 6 5}$ & $\mathbf{1 0 0 . 0 0}$ \\
\cline { 2 - 4 } & Refinery Novi Sad & 1255202 & 0.75 \\
\hline \multirow{2}{*}{ Total } & & $\mathbf{1 6 7 6 8 1 9 7 5}$ & $\mathbf{1 0 0 . 0 0}$ \\
\hline
\end{tabular}

This data is very worrying from the aspects of risk management in transporting dangerous goods and environmental protection because these sources are placed near water flows (the Sava and the Danube rivers) while source Cukarica is placed near the main Belgrade's drinking water source (in other words, its influence zone crosses the area of the main source and represents great threat for the City population).

The following part of the paper focuses on the features of demand for transportation in terms of time using road transport and is based on research conducted in 2007. A definition of demand for transport in terms of time is of great importance for defining time restriction on transporting this kind of dangerous goods in the area of Belgrade as well as for establishing a relevant period on the basis of which the features of demand for transport in terms of space are defined. These features are of primary importance for risk management in transporting dangerous goods and act as input parameters for risk analysis representing the first stage in Risk Management Methodology from the moment of accident occurrence.

\section{Features of Demand for Transport in terms of Time Using Road Transport for Carrying Oil and Oil Derivates in the Area of the City of Belgrade}

Considering the features of demand for transport which are of great significance for management in transporting dangerous goods by road, we present the distribution of demand for transport in light of the months of the year which is the variations that may appear within different months of the year, different week days and different periods of the day. In order to establish the last two types of variations (week days and periods of the day), it is necessary to define a representative period, i.e. a period reflecting a real state of demand for transport distribution during the week. In order to define the representative period, it is first necessary to establish demand for transport distribution considering the months of the year so that a suitable month for demand for transporting dangerous goods could be defined.

Fig. 4 shows demand for distributing transport considering the months of the year measured in thousands of litres and variations in demand for the months of the year using road transport for carrying oil and oil derivates within the area of Belgrade in 2007.

The question is 'Which of the presented monthly values of demand for transport is the proper one to management in transporting dangerous goods from the aspect of risk?'. Is it the lowest or highest value or the one closest to the average monthly value, that is, which month is representative for transporting oil and oil derivates within the area of Belgrade?

Considering the fact that the issue is dangerous goods, the representative month is the one during which the greatest quantity of dangerous goods is transported. This is because dangerous goods are associated with high risks and potential damages that can occur during transportation. Due to the fact that measuring risk and consequences are proportional to the quantity of transporting dangerous goods, the representative month is the one when the greatest quantity of dangerous goods is transported, which is October.

For the established period, it is also necessary to define variations in week days as well as variations that occur hourly during the day and are of great significance for defining the period when dangerous goods must not be transported. These values are compared to the values of the traffic flow measured hourly and the periods when dangerous goods must not be transported and are defined on the basis of the obtained values.

Fig. 5 represents variations on daily basis during the week when the greatest quantities of oil and oil derivates are transported in the representative month October. 


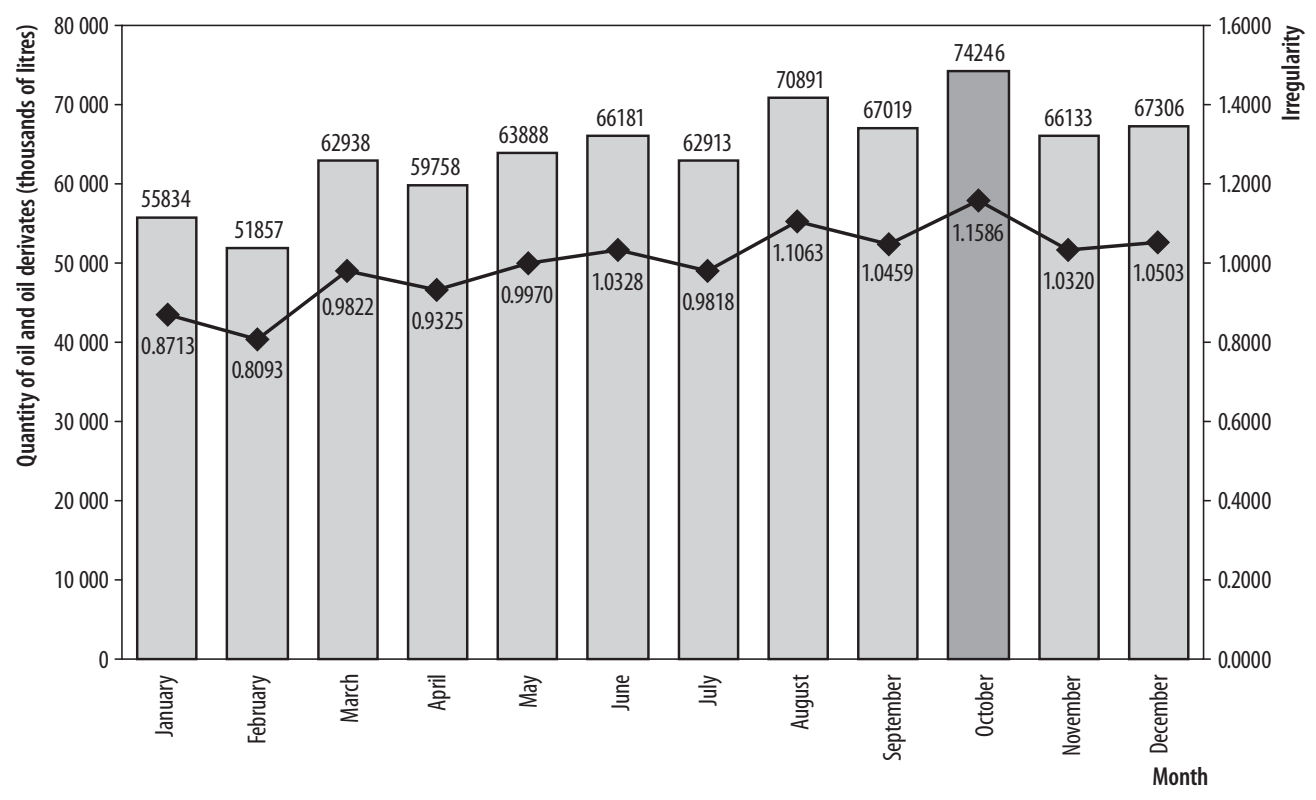

Fig. 4. Distribution of demand for transport and variations in considering the months of the year for using road transport to carry oil and oil derivates within the area of Belgrade in 2007

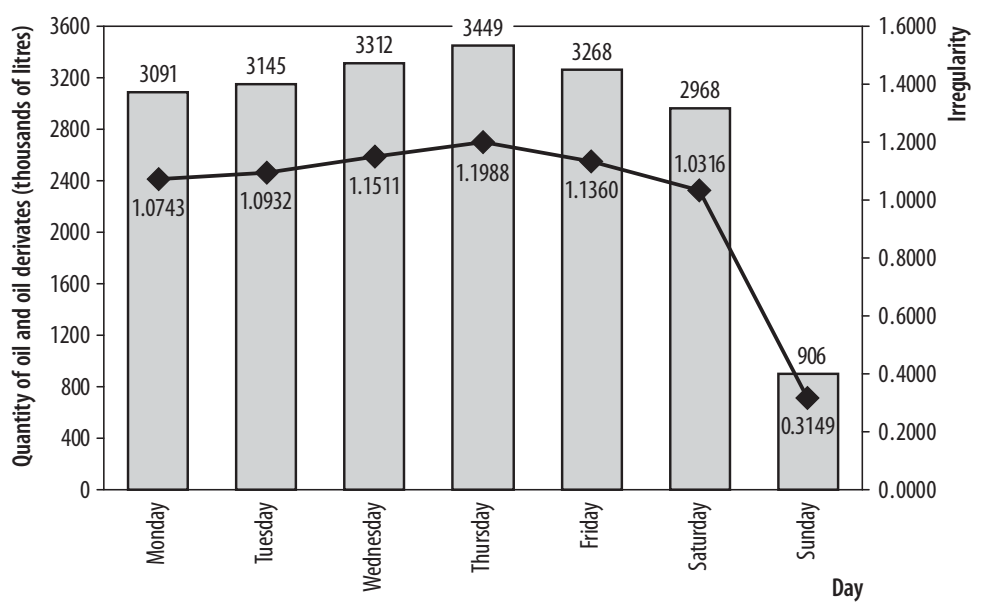

Fig. 5. Daily variations during the week

In order to define hourly variations during the day, it is necessary to define the representative day during the week on the basis of demand for distribution considering different days. As previously mentioned, it is the day when the greatest quantity of goods is transported. In our case, it is Thursday, when on a percentage basis, $19.88 \%$ more goods are transported in comparison to an average day of the representative period.

Therefore, Thursday will be the representative day for determining hourly distribution during the day as well as time restrictions on transporting dangerous goods within the area of Belgrade. This is highly significant for reducing a negative impact of dangerous goods on inhabitants as well as from the aspect of risk management in transporting dangerous goods.

Fig. 6 presents the distribution of transport demands during the day in the area of the City of Belgrade.
The greatest amount of oil and oil derivates in the area of Belgrade is transported within the period between 11.00 and 11.59 a.m. which is $14.20 \%$ of the total amount transported during the day while $12.29 \%$ is transported between 9.00 and 9.59 a.m. An interesting point is that only $4.30 \%$ of the total daily amount of goods is transported in the period from midnight to 8.00 a.m. An explanation for this data lies in the fact that petrol stations are supplied by road transport, so companies provide transport services in the period from 7.00 a.m. to midnight which is very inappropriate from the aspect of risk management because during this period, roads are crowded and the level of risk is also higher. One of the measures aimed at reducing risk level is the ban on the movement of vehicles transporting dangerous goods in the certain periods of the day as well as change in the functioning of supply regime of oil 
and oil derivates for the petrol stations in the territory of the City.

In order to determine time restrictions, beside the distribution of transport demands by hours, it is necessary to be familiar with the features and volumes of traffic flows in the city road network. As the representative city road, we have chosen one that, according to its geometrical features, satisfies demands for transporting dangerous goods (curves radii, pavement quality, traffic lane width etc.), and is featured by high traffic flows. On the basis of traffic counts conducted by the Faculty of Traffic and Transport Engineering of the Institute in Belgrade in 2006 (Vukanovic et al. 2006), Bulevar Vojvode Misica, along the route of which Belgrade's Fair takes place and which has 6598 vehicles in both directions during the peak hour (from 5.00 to 5.59 p.m.), was chosen as the representative road.

Fig. 7 presents variations in hours during the day for the chosen road.

On the basis of the presented variations in transporting oil and oil derivates and variations in traffic flow volumes considering hours during the day, a decision on the period of the day when restriction on the movement of vehicles transporting dangerous goods within the area of the City should be introduced can be made.

When the afternoon period is considered, on the basis of the previous two diagrams, it can be concluded it is necessary to introduce restrictions on the time period from 4.00 to 7.00 p.m. because at this time, traffic flows are increased while demand for transport is low and the amount makes up to $11 \%$ of total daily demands. In the morning period, restrictions should be introduced only from 8.00 to 10.00 a.m. Besides these restrictions, in order to reduce risk, it is necessary to supply petrol stations with oil and oil derivates in the area of Belgrade during night time (from midnight to $6.00 \mathrm{a}$ am.) when traffic flows are low. Consequently, the question 'What is the quantity of oil and oil derivates transported from the above mentioned sources?' arises. In order to answer the question, it is necessary to define the flows of distributing goods in terms of space which is the next point discussed by this paper.

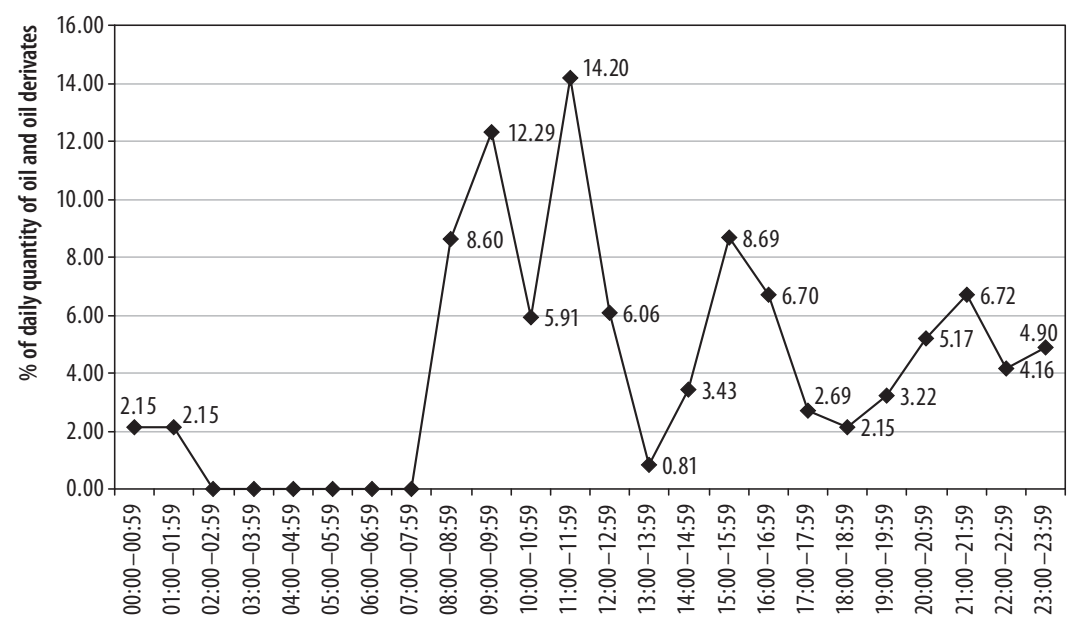

Fig. 6. Hourly variations during the day

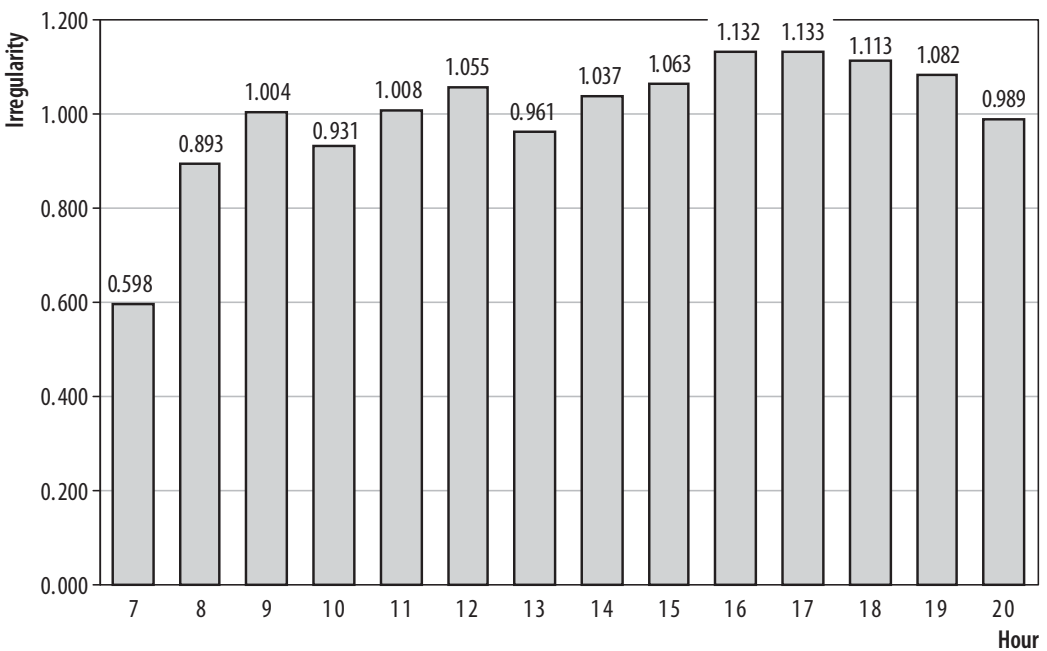

Fig. 7. Hourly variations in the traffic flow volume during the day - Bulevar Vojvode Misica 


\section{Features of Demand for Transport in Terms of Space Using Road Traffic for Delivering Oil and Oil Derivates to the Area of Belgrade}

In order to define the features of demand for traffic in terms of space, the first step to be taken is defining traffic zones for the serviced area. Criteria for creating traffic zone boundaries are as follows:

1. administrative boundaries of municipalities within the area;

2. existing boundaries of urban zones according to the purpose of their areas;

3. main roads.

On the basis of the presented criteria, the serviced area is divided into 79 zones. For the defined representative period, a spatial distribution of goods between the pairs of the zone was organized within one day (origin destination matrix). By the origin - destination matrix, it can be easily decided on the level of attractiveness, i.e. the level of the productivity of a certain zone. Due to its size, the matrix will not be presented in this paper. However, on the basis of the matrix, the features of goods flows are determined in relation to the serviced area (transit, origin - destination within the area etc.) as well as road loading (goods flow).

Fig. 8 shows the features of spatial flows of oil and oil derivates in relation to the defined serviced area.

$23.84 \%$ of the total quantity of oil and oil derivates transported to the area of Belgrade are flows the origin and destination of which are in the area of the City. The reason for a high presence of these types of flows should be sought keeping in mind the fact that there is Oil Installation in Cukarica, (source 3, Fig. 2) from which even $66.67 \%$ of the total quantity of oil and oil derivates is transported within the City area for the need of 114 petrol stations in the City. After observing flows the origins of which are placed outside the borders of the defined serviced area and their targets are within the area of Belgrade, we have reached a conclusion that the

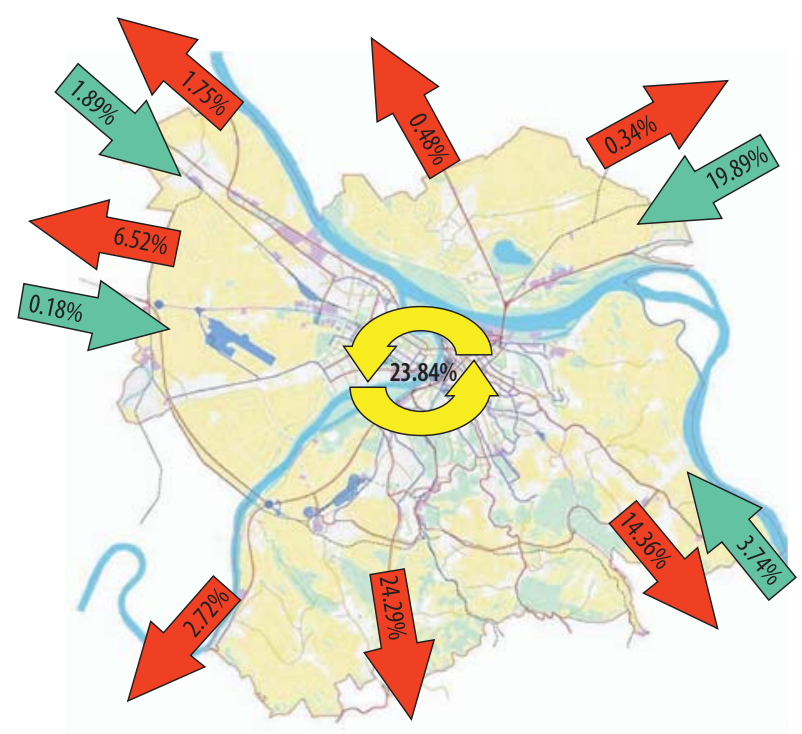

Fig. 8. Features of the spatial flows of oil and oil derivates amount of this type of spatial flows makes $25.70 \%$ of the total quantity of transported goods. Transit flows have the share of $38.74 \%$, i.e. about 1171406 litres of oil and oil derivates transits through the City area on daily basis. Flows the origin of which are in the area of Belgrade and destinations of which are outside of it, have the share of $11.72 \%$ of the total quantity of oil and oil derivates flows.

On the basis of the established share and being familiar with the distribution of transported goods taking into account daytime hours, it is possible to optimize the existing distribution of the flow of goods in terms of time by shifting the local transport of oil and oil derivates, i.e. $23.84 \%$ of daily demands to the period from midnight to $6.00 \mathrm{a} . \mathrm{m}$. The transport of the remaining quantity of goods should be done during the rest of the day, except from 7.00 a.m. to 9.00 a.m. and from 4.00 to 7.00 p.m.

The last but not least important feature of the spatial distribution of demand for transport is defining the load of the existing road network with goods flows during the representative day, i.e. defining goods flows using certain roads. Fig. 9 presents the load of the road network in the City area expressed in thousands of litres daily that is on the basis of matrix origin - destination.

From this figure, it can be concluded that the most loaded road is Bulevar Vojvode Misica with the daily flow of 17958000 litres of oil and oil derivates. The reason for such a great load lies in the fact that this road is placed close to Oil Installation Cukarica, and therefore represents a part of the route for transporting dangerous goods where a large percentage of transit flows towards the southern part of the City is transported. The second road heavily loaded with oil and oil derivates is Pancevacki most (northern part) along which 16871000 litres of oil and oil derivates is transported daily. This road takes the greatest quantity of goods entering the area of Belgrade because vehicles transporting oil and oil derivates from Oil Refinery Pancevo use this road (bridge) to enter the City area.

Without knowledge of the features of demand for transport presented in this paper, no possibility of efficiently managing risks from possible accidents exists. The data represents input to defining routes for the movement of vehicles transporting dangerous goods. A definition of these features represents the first stage of risk analysis in transporting dangerous goods.

\section{Conclusions}

1. On the basis of research, it has been established that considering all transport modes by which oil and oil derivates were transported within the area of Belgrade in 2007 , the greatest share had road transport with $77.36 \%$ of the total quantity of transported goods.

2. Taking into account all sources, most of oil and oil derivates using road transport have been transported to the area of Belgrade from Oil Refinery Pancevo $41.66 \%$ while $30.25 \%$ of the total quantity of oil and oil derivates has been transported from Installations in Belgrade (Cukarica, Ada Huja, and Novi Beograd). 


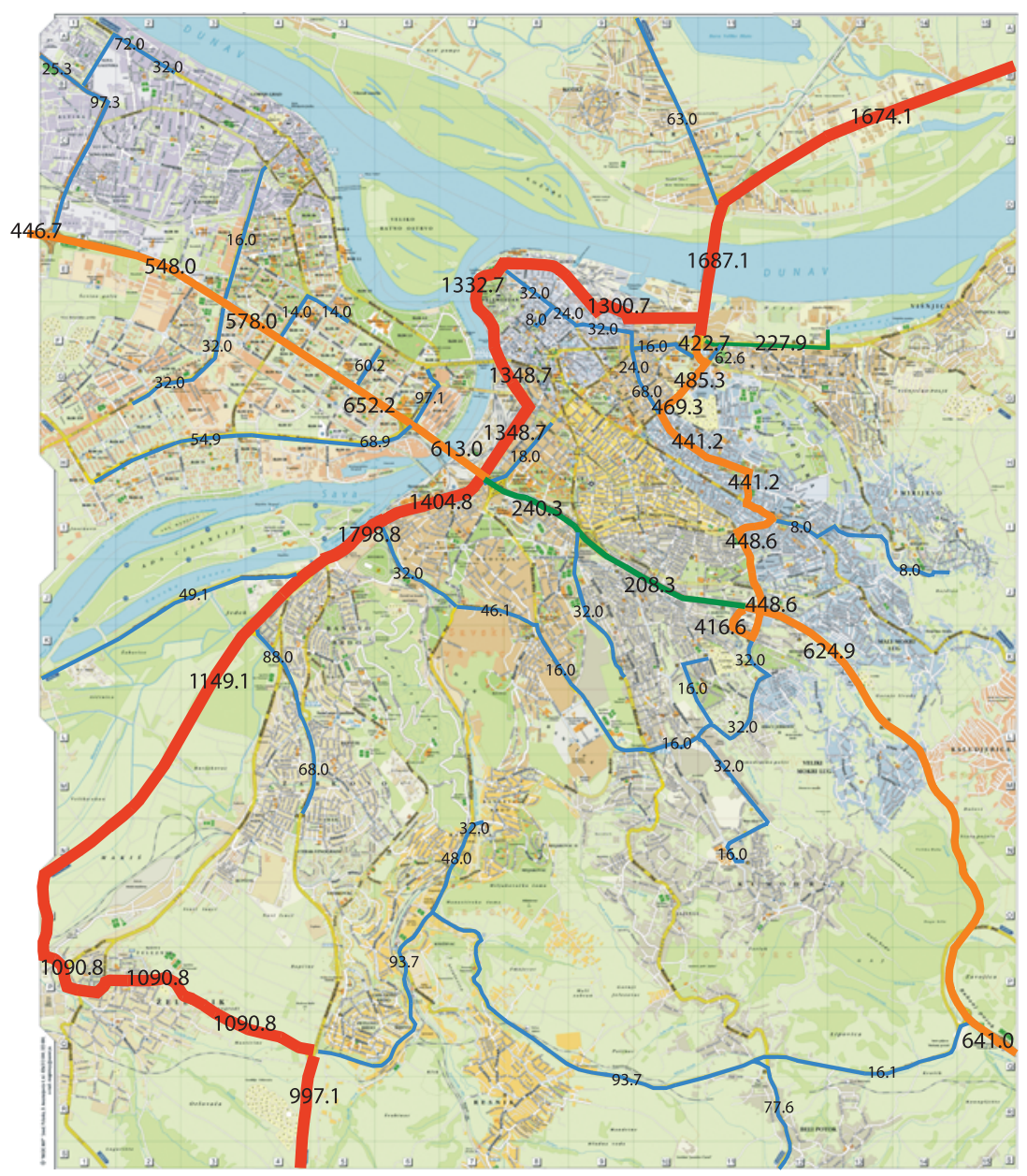

Fig. 9. Oil and oil derivates flow on the City roads (in thousands of litres)

3. The researches have established that the period of the year has an impact on the size of demand for transport. Consequently, demand for transport is the highest at the end of summer and during autumn, i.e. in the period from August to December while the winter period records sharp decline in demand for transport.

4. October is the month when demand for transport is the highest as within this period demand for transport is $15.86 \%$ which is more than in an average month while in February it makes $19.07 \%$ less than on average.

5. Recorded variations in demand for transport considering different months of the year, i.e. great discrepancies in the size of demand for transport in terms of the months of the year amounting up to $40 \%$ between the month having highest and lowest demand for transport, highly complicate management in transporting oil and oil derivates within the area of Belgrade. In other words, they require additional measures in organizing the transportation of these types of goods aimed at reducing variations in months because for risk management, only the highest monthly value is valid and in case it substantially differs from the lowest and medium value, the engagement of more re- sources is needed in order to prevent the occurrence of accidents, i.e. in order to reduce the probability of accident occurrence and the size of possible consequences (availability of greater number of fire-fighter brigades, ambulance vehicles etc.).

6. Variations in week days show that there are no large discrepancies. However, what is very adverse from the aspect of risk is the fact that demands at weekend are very low, i.e. Sunday has a share of only $30 \%$ of an average day of the week. Considering the fact that traffic flows are the lowest on Sundays, it is necessary to increase demand for transport for this particular day making the redistribution of demand for transport in view of days, i.e. by reducing demand for transport on weekdays when it is higher than the average and shifting it to Sunday. In other words, it is necessary to balance demand for transport in view of week days with the aim at reducing variations.

7. The analysis of demand for transport in terms of hours has revealed that within the day, when risk is the lowest (from midnight to $6.00 \mathrm{a}$ a.m.), this type of dangerous goods is not transported, i.e. it makes less than $5 \%$ of the total daily quantity. Percentage is lower by $18 \%$ than the quantity of goods transported from Installations to the area of Belgrade for the needs of 
supplying petrol stations within the city which is inadmissible from the aspect of risk management. If we observe the paired data on the size of traffic flows and considering the hours and quantities of transported goods, it can be concluded that $8.60 \%$ of the total daily quantity is transported in the period of morning peak hours (from 8.00 to 9.00 a.m.) while about $11 \%$ is transported during afternoon peak hours (from 4.00 to 7.00 p.m.). As one of the measures for reducing operational risk, there is a suggestion of banning transport to carry these types of goods in time intervals from 8.00 to 10.00 a.m. and from 4.00 to 7.00 p.m. which demands core changes in organizing the transportation of these types of goods.

8. The definition of the features of demand for transport in terms of space by means of matrices origin provides that destination enabled the determination of flow features in relation to the defined serviced area while somewhat more than $23 \%$ are local and more than $38 \%$ are transit flows. The aim of spatial analysis is the determination of flow structures in terms of space and finding solutions for reducing risk to the lowest possible level. This could be achieved by shifting transit to bypass directions in order to disburden the City area as well as to reduce the level of risk which may affect the inhabitants and environment in the City.

\section{References}

Batarliene, N. 2008. Risk analysis and assessment for transportation of dangerous freight, Transport 23(2): 98-103. doi:10.3846/1648-4142.2008.23.98-103.

Batarliené, N. 2007. Implementation of advanced technologies and other means in dangerous freight transportation, Transport 22(4): 290-295.

Ghazinoory, S.; Kheirkhah, A. S. 2008. Transportation of hazardous materials in Iran: A strategic approach for decreasing accidents, Transport 23(2): 104-111. doi:10.3846/1648-4142.2008.23.104-111.

Leonelli, P.; Bonvicini, S.; Spadoni, G. 2007. Hazardous materials transportation: a risk-analysis-based routing methodology, Journal of Hazardous Materials 71(1-3): 283-300.

Skupština grada Beograda. 2003. Generalni plan Beograda 2021. (Approved 2003). [General Plan of Belgrade till 2021], Institute of Urbanism Belgradee (in Serbian).

United Nations Environment Programme. 2000. TransAPELL: Guidance for Dangerous Goods Transport Emergency Planning in a Local Community (Technical Report 35). Division of Technology, Industry, and Economics. Paris, France. Available from Internet: <http://www.unep.fr/shared/publications/pdf/2679-TransApellEN.pdf $>$.

Vukanovic, S.; Jovic, J.; Stanic, B. et al. 2006. Istraživanje karakteristika saobraćaja na jedinstvenoj uličnoj mreži grada Beograda za 2006. godinu [Research of the Traffic Features at the Unique Street Network of the City of Belgrade for 2006], Belgrade (in Serbian). 